Supporting Information

\title{
MCM-22 zeolite-induced synthesis of thin sodalite zeolite membranes
}

Xue-Ling Wei $i^{a}$,Wen-Yan Pan ${ }^{a}$, Xingyang Li ${ }^{a}$, Meng Pan ${ }^{a}$,

Chao-Fei Huo ${ }^{a}$, Renchun Yang ${ }^{a}$, Zi-Sheng Chao ${ }^{b^{*}}$

${ }^{a}$ College of Biological and Chemical Engineering, Anhui Polytechnic University, Wuhu, Anhui 241000, China

${ }^{b}$ College of Materials Science and Engineering, Changsha University of Science \& Technology, Changsha, Hunan 410114, China

*Corresponding authors: Prof. Zi-Sheng Chao;

Tel \& Fax:+86-731-88713257;

E-mail:zschao@yahoo.com; chao_zs@aliyun.com 


\section{Effect of alkalinity on the formation of sodalite zeolite membrane}
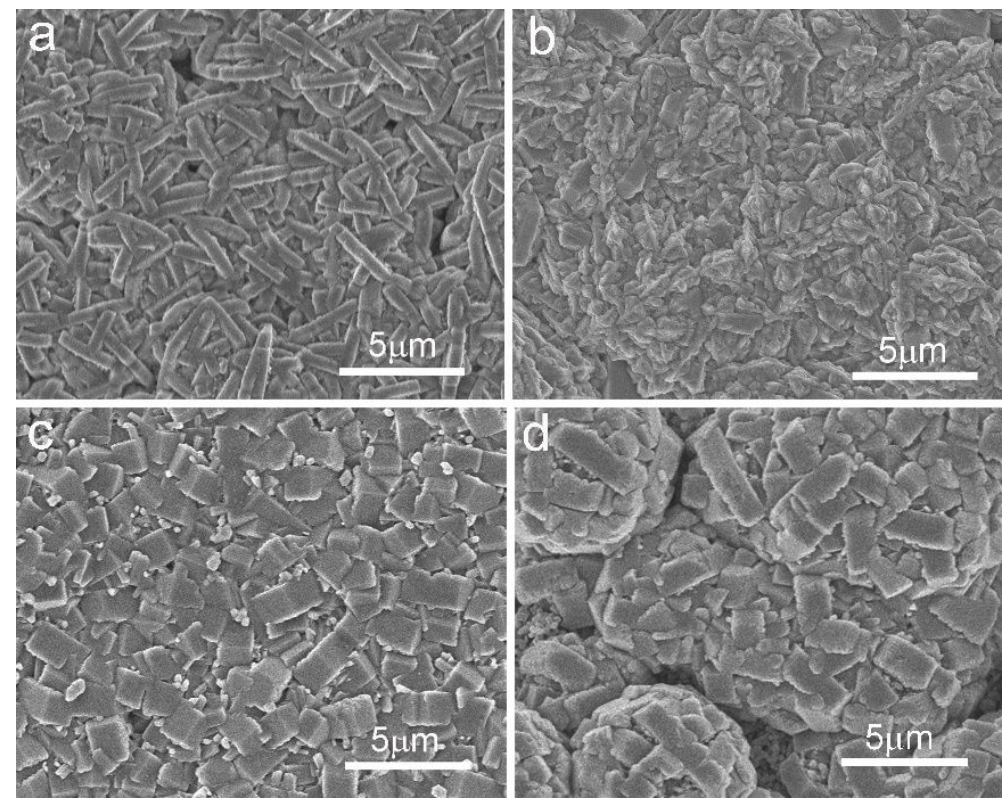

Fig. S1 SEM micrographs of sodalite zeolite membranes synthesized at $140{ }^{\circ} \mathrm{C}$ for $4 \mathrm{~h}$ from the synthesis sol with various alkalinities over MCM-22 zeolite-modified support. The molar compositions of synthesis sol are $\mathrm{x} \mathrm{Na}_{2} \mathrm{O}: 1 \mathrm{Al}_{2} \mathrm{O}_{3}: 5 \mathrm{SiO}_{2}: 1005 \mathrm{H}_{2} \mathrm{O}$, where $\mathrm{x}=$ (a) 40, (b) 45, (c) 50 , and (d) 55 .

Fig S1 shows the SEM micrographs of sodalite zeolite membranes synthesized from the synthesis sols with molar compositions $x \mathrm{Na}_{2} \mathrm{O}: 1 \mathrm{Al}_{2} \mathrm{O}_{3}: 5 \mathrm{SiO}_{2}: 1005 \mathrm{H}_{2} \mathrm{O}$ (x $=40 \sim 55)$ at $140{ }^{\circ} \mathrm{C}$ for $4 \mathrm{~h}$. One can see that, in all the cases, a continuous sodalite zeolite layer has been formed over the support. At the lower alkalinity $(x=40)$, there are a few larger-sized defects in the membrane (Fig. S1 a). With increasing the alkalinity of synthesis sol $(X=45$ and 50$)$, the amount and size of defects both decrease and the crystal size of sodalite zeolite increases (Fig. S1 b and c). It indicates that the higher alkalinity is beneficial to the growths of zeolite crystals and zeolite membrane ${ }^{1}$. However, when the alkalinity of synthesis sol $(x=55)$ is too high (Fig. S1 d), the size distribution of sodalite zeolite crystals becomes uneven, with many smaller-sized sodalite zeolite crystals being generated, which leads to the appearance of a few much larger-sized defects in the zeolite membrane. This result can be due to the fact that when the alkalinity of synthesis sol is too high, on the one hand, a proportion of zeolite crystals are erodes or even dissolved; on the other hand, the 
silicon/aluminum active ingredients are predominantly consumed in the generation and growth of zeolite crystals in the bulk solution rather than over the surface of support ${ }^{2}$.

Accordingly, it is concluded that the optimal alkalinity of synthesis sol is $\mathrm{x}=50$ in the molar composition $x \mathrm{Na}_{2} \mathrm{O}: 1 \mathrm{Al}_{2} \mathrm{O}_{3}: 5 \mathrm{SiO}_{2}: 1005 \mathrm{H}_{2} \mathrm{O}$.

\section{Effect of temperature on the formation of sodalite zeolite}

\section{membranes}

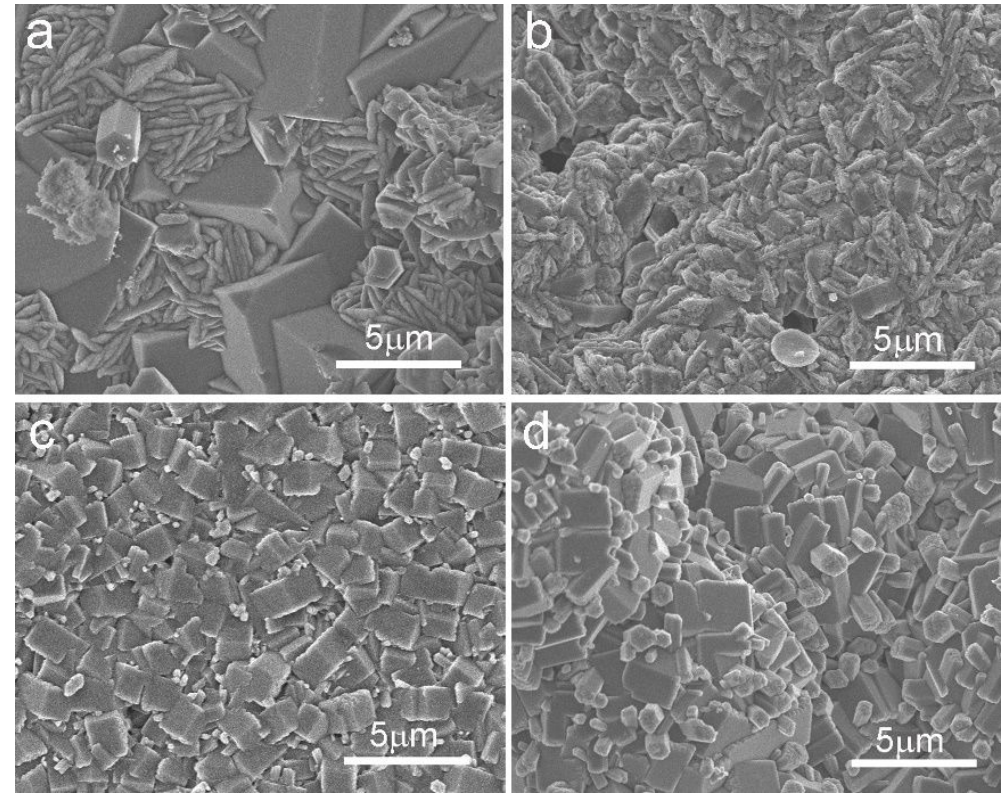

Fig. S2 SEM micrographs of sodalite zeolite membranes synthesized for $4 \mathrm{~h}$ at various temperatures. (a) $120{ }^{\circ} \mathrm{C}$, (b) $130{ }^{\circ} \mathrm{C}$, (c) $140{ }^{\circ} \mathrm{C}$, and (d) $150{ }^{\circ} \mathrm{C}$. The molar composition of synthesis sol is $50 \mathrm{Na}_{2} \mathrm{O}: 1 \mathrm{Al}_{2} \mathrm{O}_{3}: 5 \mathrm{SiO}_{2}: 1005 \mathrm{H}_{2} \mathrm{O}$.

Fig S2 shows the SEM micrographs of sodalite zeolite membranes synthesized at various temperatures for $4 \mathrm{~h}$. The synthesis sol has a molar composition $50 \mathrm{Na}_{2} \mathrm{O}: 1$ $\mathrm{Al}_{2} \mathrm{O}_{3}: 5 \mathrm{SiO}_{2}: 1005 \mathrm{H}_{2} \mathrm{O}$. One can see that, the membrane synthesized at the lower temperature $\left(120^{\circ} \mathrm{C}\right)$ consists of smaller irregular and larger rectangular crystals (Fig. $\mathrm{S} 2 \mathrm{a}$ ). The membrane is continuous but its surface is very rough, and also, it contains a few very large defects, which are caused by the stacks of different-shaped and -sized zeolite crystals. With increasing the synthesis temperature $\left(130\right.$ and $\left.140{ }^{\circ} \mathrm{C}\right)$, the sodalite zeolite increases gradually in crystal size and its crystal morphology turns 
into regular cube, while the other types of zeolite disappear. (Fig. S2 b and c). Besides, the surface of membrane becomes relatively flat, and the size and number of defects in the membrane decreases obviously, as the synthesis temperature increases. However, when the synthesis temperature reaches $150{ }^{\circ} \mathrm{C}$ (Fig. S2 d), some hexagonal impurities are generated, besides the sodalite zeolite crystals. In addition, the surface of membrane becomes uneven and rough, with the appearance of large-sized valley-like defects in the membrane.

Accordingly, it is concluded that neither a too low nor a too high temperature is helpful to growth of sodalite zeolite ${ }^{3}$ and thus the corresponding membrane. Therefore, the optimal synthesis temperature for sodalite zeolite membrane is $140^{\circ} \mathrm{C}$.

\section{Effect of synthesis time on the formation of sodalite zeolite}

\section{membranes}
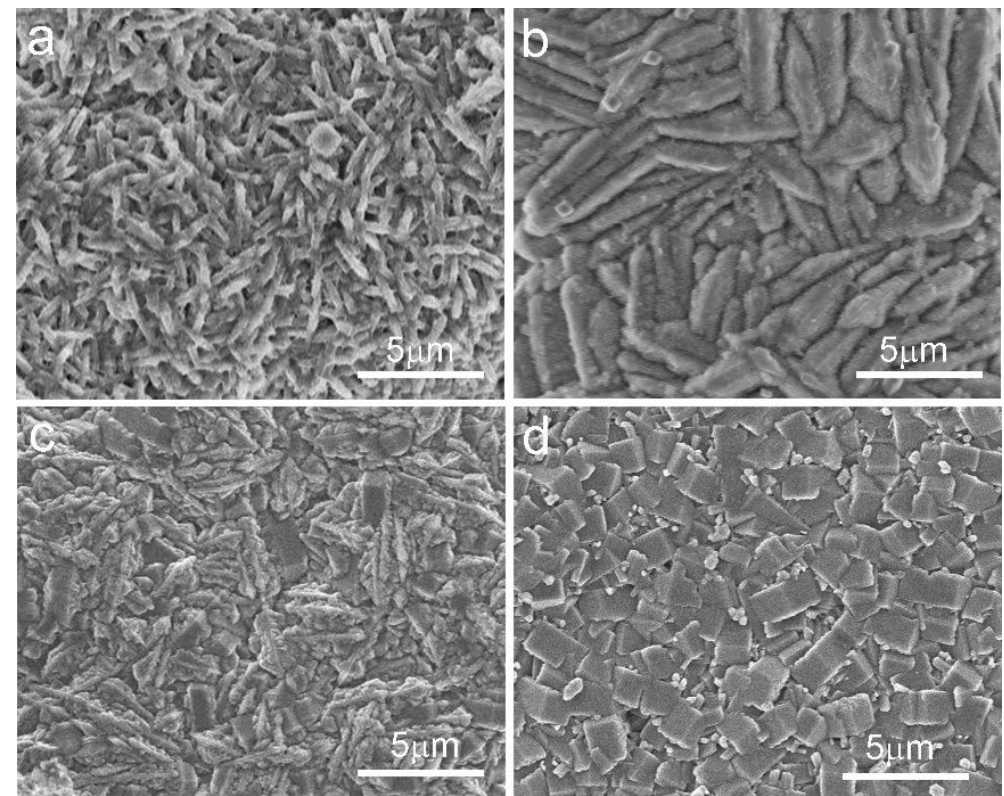

Fig. S3 SEM micrographs of sodalite zeolite membranes synthesized at $140{ }^{\circ} \mathrm{C}$ for various periods of time. (a) $1.5 \mathrm{~h}$, (b) $2 \mathrm{~h}$, (c) $3 \mathrm{~h}$ and (d) $4 \mathrm{~h}$. The molar composition of synthesis sol is $50 \mathrm{Na}_{2} \mathrm{O}: 1$ $\mathrm{Al}_{2} \mathrm{O}_{3}: 5 \mathrm{SiO}_{2}: 1005 \mathrm{H}_{2} \mathrm{O}$.

Fig S3 shows the SEM micrographs of the sodalite zeolite membranes synthesized at $140{ }^{\circ} \mathrm{C}$ for various periods of time. The synthesis sol has a molar composition $50 \mathrm{Na}_{2} \mathrm{O}: 1 \quad \mathrm{Al}_{2} \mathrm{O}_{3}: 5 \mathrm{SiO}_{2}: 1005 \mathrm{H}_{2} \mathrm{O}$. One can see that for the shorter 
synthesis period of time $(1.5 \mathrm{~h})$, the membrane consists of rod-like sodalite zeolite crystals, and the loose and random stacking of sodalite crystals leads to the presence of large defects in the membrane (Fig. S3 a). With prolonging the synthesis period of time $(2 \sim 4 \mathrm{~h})$, the morphology of sodalite zeolite crystals turns gradually into spindle (Fig. S3 b), irregular particulate (Fig. S3 c) and cube (Fig. S3 d). Meanwhile, the membrane becomes more compact, with less defects being present in the membrane.

It indicates that the prolonging of synthesis period of time benefits the growth of sodalite zeolite and thus the formation of compact sodalite zeolite membrane ${ }^{4}$. For energy-saving reason, the synthesis period of time has been set to $4 \mathrm{~h}$ for all the runs of synthesizing sodalite zeolite membranes in this work. 


\section{References}

(1) Lai, L.; Shao, J.; Ge, Q.; Wang, Z.; Yan, Y., The preparation of zeolite NaA membranes on the inner surface of hollow fiber supports. J Membrane Sci 2012, 409, 318-328.

(2) Bosnar, S.; Subotic, B., Mechanism and kinetics of the growth of zeolite microcrystals. Micropor Mesopor Mat 1999, 28, (3), 483-493.

(3) Khajavi, S.; Kapteijn, F.; Jansen, J. C., Synthesis of thin defect-free hydroxy sodalite membranes: New candidate for activated water permeation. J Membrane Sci 2007, 299, (1), 63-72.

(4) Nabavi, M. S.; Mohammadi, T.; Kazemimoghadam, M., Hydrothermal synthesis of hydroxy sodalite zeolite membrane: Separation of $\mathrm{H}_{2} / \mathrm{CH}_{4}$. Ceram Int 2014, 40, (4), 5889-5896. 